\title{
Journeys of Transcultural Literacies: Working Toward Transformative Learning in Adult Literacy Education
}

Karen Magro, The University of Winnipeg

\begin{abstract}
Transformative learning involves significant personal and social growth. Globalization, immigration, changes in socioeconomic patterns, geopolitical tensions, and advances in technology challenge teachers to understand and mobilize the changing dynamics, practices, and contexts of learning and literacy in more complex ways (Luke \& Elkins, 2002). Transcultural literacies acknowledge multiple dimensions of literacy learning that build upon learners' unique talents and aspirations. The use of powerful texts that highlight local and global themes can resonate with adult learners coming from diverse cultural backgrounds. Connections between transcultural literacies and dimensions of transformative learning are highlighted in this study.
\end{abstract}

This research study was motivated by my own observations of literacy and learning in a time of increased immigration and cultural diversity, and the reality that adult literacy classrooms should be reflecting these changes (Magro \& Ghoryashi, 2011). Dagnino (2012) writes that "physical and virtual mobility has indeed become the main trope of societies characterized by 'superdiversity' and the dynamic interplay of alternative/ multiple modernities" (p.2). Along these lines, Pennycook (2007) defines transculturalism as "the fluidity cultural relations across global context" (p.91). Global flows, transnational interactions "loosen local populations from geographically constrained communities, connecting people and places around the globe in new and complex ways" (Miller, 2006, p.1). Miller suggests that these dynamic flows and mobilities open up new possibilities for a "worldwide" curriculum that disrupts the status quo and embraces plurality and social justice.

Transcultural literacies explore the connections literacies between local ecologies and global events (Orellana, 2016). Honeyford and Watt (2017) write that now, more than ever, teachers in both urban and rural areas are seeking new texts and learning resources that better reflect the linguistic and cultural pluralism that exists today. Too often, historically marginalized youth and adults have been harmed by educational institutions; these students have suffered from colonial, racist, sexist, elitist, and homophobic abuse that may have caused them to abandon "traditional" education. 
A transformative shift in literacy learning would work to discover and strengthen learners' existing literacies, talents, and experiences. In particular, a key challenge for teachers is to help their students interrogate and understand the way these forces interact and impact their own lives, since local knowledge is always linked in some way to the "dynamic flow of more global, sociocultural, economic, and political forces" (Honeyford \& Watt, p.4).

This study explores the important connections between transformative theories of adult learning and transcultural literacies. How do teachers conceptualize their role and responsibility as adult literacy educators? What values, beliefs, and ideals guide their practice? To what extent do the changing social, cultural, and geopolitical landscapes inform educators' pedagogical decision making in terms of text choices and curriculum resources for adult learners? What do they hope that adults in their classes will learn? Do the educators have preferred teaching and learning strategies that create a positive learning climate in a time of great change?

\section{Trajectories of Immigration: Understanding the Context of This Study}

Relationships between adult learners, teachers, and administrators in educational systems can be viewed with new potential. In an increasingly globalized world, transcultural literacy learning challenges educators to explore linguistically and culturally diverse pedagogies. Geopolitical shifts in power, conflict and war, environmental deterioration, and perceived economic prosperity and improved quality of life make North America a destination for thousands of migrants. There are now about 192 million people living outside their place of birth; countries like Canada are increasingly becoming the final destination for a growing number of migrants, both forced and voluntary (Magro \& Ghorayshi, 2011). Its population continues to reflect the changing patterns in immigration and resettlement worldwide. For example, estimates project that 1 in every 3 Canadians will be born outside of Canada in the next decade (Government of Canada, 2016).

This study was completed in Winnipeg, Manitoba. As the geographic center of Canada, the changing demographics in Winnipeg reflect wider changes in immigration throughout Canada and in North America. For example, in 2016, immigration to Manitoba increased to $23.8 \%$; this increase was attributed in part to the 1,233 Syrian refugees that resettled in Manitoba because of the National Syrian Refugee Resettlement initiative. Indeed, "of all permanent residents to Manitoba in 2016, 22.2 per cent landed as refugees and protected persons $(3,370)$, the highest number of refugees since 1990 and the highest number in Canada" (Immigrants Facts Manitoba, 2016). In addition to financial hardship and the loss of one's homeland, refugees are often recovering from trauma and loss (Magro, 2016; Magro \& Ghorayshi, 2011). Community support, education, and counseling for children, youth, and adults are a vital part of helping these newcomers establish themselves in Canada.

Linguistic and cultural diversity are also on the rise in Winnipeg and other major cities and rural regions in Canada. In 2016, 52.4\% of Manitoba's new permanent residents arrived from Asia and the Pacific regions, followed by Africa and the Middle East (32\%), Europe (10\%), and South and Central America (3.6\%). In addition to English and French, the top ten languages spoken by newcomers included Tagalog, Punjabi, Tigrinya, Arabic, Russian, Chinese, Gujarati, Somali, Urdu, Korean, Yoruba, and Spanish. While many economic immigrants possess the skills and 
knowledge that would enable them to successful secure positions in engineering, the natural and applied sciences, business and finance, and trades and transport, other newcomer adults seek out adult education as a first step in completing Grade 12 and moving forward with their professional or technical education.

The challenge is for adult educators to be sensitive and aware of current political situations and the psychological and situational barriers (e.g., financial hardship, the loss of one's family and livelihood in the case of many refugees) that can impede learning (Magro \& Ghorayshi, 2011). In discussions, teachers could be more open to integrating viewpoints relating to different cultural backgrounds. A willingness to make meaningful connections with adult learners in an effort to understand their complex histories and backgrounds is a starting point.

\section{Literature Review}

Significant parallels and similarities can be drawn between theories of transformative learning and transcultural literacies. The central ideas of transformative learning reinforce and support the emerging literature on transcultural literacies. A common thread connecting the two is the emphasis on expanding ways of knowing that acknowledge and even encourage critical reflection, creativity, ambiguity, and complexity. A transformative approach to teaching adult literacy would enable learners to "develop a critical awareness of social structures and powerful discourses and their impact on the construction of individual subjectivities" (Jarvis, 2006, p. 69). A potentially transformative process could be encouraged by adult educators in their curriculum choices and preferred teaching and learning strategies.

Along these lines, transcultural literacies highlight a creative way of looking at learning processes and education; they can be conceptualized as dynamic personal, social, and cultural spaces where new ways of knowing, thinking, and acting can emerge. In English language arts, knowledge can be communicated through storytelling, poetry, art, creative writing, and drama. Short (2016) writes that the use of global literatures, for example, can help students "break cycles of oppression and prejudice between diverse cultures" (p. 10). Texts have the potential to be transformative if learners are given opportunities to dialogue and reflect upon the way that characters solve problems and manage life challenges (Jarvis, 2006; Short, Day, \& Schroeder, 2016).

This study is grounded in the transformative perspective of adult literacy, which is a lifelong journey that enables individuals to meet "the challenges and complexities of life, culture, the economy, and society" (UNESCO, 2010, p.38). A transformative approach to adult literacy learning highlights an "asset" view of learning; there is an invitation for adult learners to bring into the classroom context their own experiences, narratives, languages, identities, cultural artefacts, music, and aspirations (Freire, 1993; Miller 2006). Transformative teaching is culturally responsive teaching and it involves a creative dynamic that factors in local and world events (Taylor, 2006). Educators also need to become more aware of the way overlapping sites of learning (e.g., the workplace, families, spiritual organizations, prison systems, voluntary agencies, film and television, new technologies, etc.) influence learning processes.

A transformative curriculum would encourage and value adult learners' visions and support transcultural learning. It would support learners as they work to "define shared interests and 
common values across cultural and national borders" (Slimbach, 2005). Not only would a transformative curriculum grounded in transcultural learning be vitally important to the learner, but also it could serve to engage learners in efforts to address global challenges.

Adult learning centres (ALCs) can be havens of creativity and resilience when a climate of respect and intercultural competence is transformed from an ideological construct into everyday actions enacted by individuals. Global awareness, world learning, foreign language proficiency, empathy and transcultural understandings are among the skills that individuals can learn to develop (Slimbach, 2005). Giroux (1993) further notes asserts that central to learning "is the need for students to understand how cultural, racial, ethnic, and ideological differences enhance the possibility for dialogue, trust, and solidarity" and that "literacy must be rewritten in terms that articulate differences with the principles of equality, justice, and freedom rather than with those interests supportive of hierarchies, oppression, and exploitation" (p. 368). New literacies evolve because of the continual interaction with the physical, social, and cultural environment (Luke \& Elkins, 2002). Transcultural literacies acknowledge "hybrid identities" and "cultural fusion" which can result from these interactions (Cuccioletta, 2001/2002).

Transcultural literacies embrace the importance of understanding and valuing underrepresented narratives. For example, Graham Reynold's (2016) Viola Desmond's Canada: A History of Blacks and Racial Segregation in the Promised Land details the racism that African-Canadians faced as they fled the United States in search of a safe haven. This can be compared with the narratives presented in Isabel Wilkerson's (2010) The Warmth of Other Suns recounting the "great migration" (1920-1970s) of African-American people from the southern states to find a better life and the protection of their civil rights in cities such as Chicago, Detroit, and New York. Under reported narratives provide individuals with opportunities to challenge cultural stereotypes and misconceptions. Chimamanda Ngozi Adichi (2015) recognizes the value of understanding complex and unique narratives:

Stories matter. Many stories matter. Stories have been used to dispossess and malign, but stories can also be used to empower and to humanize. Stories can break the dignity of a people, but stories can also repair that broken dignity...when we reject the single story, when we realize that there is never a single story about any place, we regain a kind of paradise. (p. 22)

Adichie's message has particular relevance for teachers who hope to create a truly culturallyinclusive classroom.

\section{Connections between Transcultural Literacies and Transformative Learning}

Transcultural literacy learning is a transformative process that opens up new possibilities for understanding the multi-layered dynamics of literacy and transcultural learning (Cranton, 2006). The idea of significant personal transformation and openness to new perspectives is at the heart of transformative learning (Mezirow, Taylor, \& Associates, 2009). For Mezirow (1981), social change is rooted in individual perspective transformation. As a facilitator, mentor, and challenger, the adult educator can help individual learners "realize their potential for becoming more liberated, socially responsible, and autonomous" (Mezirow, 2000, p. 30). Learning objectives may be personal (e.g., such as getting a better job or helping) or social (e.g., organizational change, community development, etc.).

Drawing from both the humanistic and 
constructivist perspectives of learning, transformative learning is a "deeper level" learning that, as Clark (1993) writes, "produces more far-reaching changes in the learners than does learning in general, and that these changes have a significant impact on the learner's subsequent experiences” (p. 47). King (2005) further asserts that "the roots of transformative learning are found in the critical reflection of the being and self" (p. 32). In an educational climate of trust, they can ask difficult questions of themselves and others. O'Sullivan and his associates (2002) suggest that transformative learning "involves experiencing a deep, structural shift in the basic premises of thought, feeling, and actions. It is a shift of consciousness that dramatically and permanently alters our way of being in the world" (p. 11).

Mezirow's (1981; 1991) theory of transformative learning describes how individuals interpret, construct, validate, and reappraise their experiences. For Mezirow (1981, 1991), learning includes not only the acquisition of new information, but also how we understand, analyze, and interpret our world. Individuals can "reframe" their perspectives through problem solving, action learning, critical self-reflection gained from applying insights learned from another person's narrative to their own experiences, or through the exploration of thought and feeling in psychotherapy (Mezirow and Associates, 2000). "Reflection is the central dynamic involved in problem solving, problem posing, and transformation on meaning schemes and meaning perspectives” (Mezirow, 1991, p. 116).

Transcultural literacies and transformative learning processes are dynamic, evolving, and interconnected to community, cultural, social, psychological, and geographical contexts.
Slimbach (2005) writes that transcultural learning is not simply about "adding to a knowledge base of different cultures and ways of beings"(p.213); instead, it involves a deeper level awareness that values "the true, the good, and the beautiful wherever it is found" (p.213). Transcultural learning involves "[thinking] outside the box of one's motherland, seeing many sides of every question without abandoning conviction, and allowing for a chameleon sense of self without losing one's cultural center" (Slimbach, 2005, p. 211). Within the context of this study and the teaching of English language arts, adult literacy educators would provide opportunities for students to reflect on their readings and discussions.

\section{Methodology and Data Collection}

This qualitative study draws upon phenomenology and narrative inquiry. Merriam (2007) writes that "in the same way that ethnography focuses on culture, a phenomenological study focuses on the essence of the structure of an experience" (p. 7). van Manen further writes: "a phenomenology that is "sensitive to the life world explores how our everyday involvements with our world are enriched by knowing in-being" (p. 13). He explains that phenomenological interviews have the potential to be transformative as new ideas and perspectives emerge in the discussion. I wanted to learn more about adult educators' experiences as they continue to adapt to meet the changing demographics of adult learners in Manitoba. I wanted to better understand the dynamic interplay between learners, teachers, texts, and adult literacy education practices. The adult literacy educators that I interviewed were deeply committed to social justice education and adult literacy advocacy. Many of their students had experienced hardship in life: chronic 
unemployment, domestic violence, mental health challenges such as depression and anxiety, and poverty. Embarking on a new educational path was an initial step in "reclaiming" their lives and building a stronger future for themselves and their children.

The interview data was collected between 2015-2017. I kept detailed research notes of my interviews with the educators; in addition, I audio-taped, transcribed, and analyzed each interview looking for emerging themes such as expanding perspectives through global literature; teaching for change; educators as advocates and challengers; and creative teaching strategies that tapped into imaginative and emotional dimensions of learning. The teachers provided me with pedagogical artifacts such as project outlines, assignment questions, resources, texts, and examples of student writing. The interview process was not "formulaic" but rather more of an openended discussion that explored themes connected to transformative education, social justice, and creating a culturally inclusive curriculum for adult learners.

Five teacher participants' perspectives are presented in this study. I felt that their perspectives best reflected the ideas and themes from the larger participant group of ten. The teachers in this study had 15 years or more of experience working with adult literacy learners. They worked in culturally diverse centres with students who were not only Canadian born, but also came from Africa, Asia, the Middle East, South and Central America. These educators also worked with First Nation, Metis, and Inuit learners.

I met these teachers in my role as a consultant, volunteer, conference presenter, and through connections with the teachers I made. The 90-minute interviews explored the educators' perspectives on their role and responsibilities, the decision making that factored into the educators' specific pedagogical choices of texts and resources, their preferred teaching and learning strategies, and the way the changing cultural, social, and political climate informs their teaching and their students' learning. I drew upon van Manen's description of the art of the researcher in the hermeneutic interview. A key goal "is to keep the question (of the meaning of the phenomenon) open, to keep himself or herself and the interviewee oriented to the substance of the thing" (p. 98). I was mindful of Kvale's (1996) concept of the "inter view" which emphasizes the interchange of ideas between two individuals regarding ideas of mutual interest. Pseudonyms are used in the following excerpts.

A fundamental aim in qualitative research is discovery. I analyzed the data collected from the interviews according to concepts, metaphors, and images that the teachers shared about their teaching roles, experiences, and pedagogical insights. Conceptual analysis in phenomenological research is concerned with the nuanced content of linguistic expression (Honeyford \& Watt, 2017). In re-reading the interview transcripts, I looked for recurring words, themes, and images that provided an insight into the teachers. Learning as a journey, bridging cultural divides through world literature, adult learning as a process of reclaiming selfhood, fostering engagement, motivation, and personal agency, and learning as imagining new life possibilities were among the themes that best reflected the educators' intent to encourage their students to "read and write their worlds" (Freire, 1997). I then linked these themes to the theoretical perspectives from transformative learning theories and transcultural literacies. 


\section{Findings}

Each teacher's perspective suggest teaching and learning approaches that would encourage adult learners to investigate and explore complex issues and ideas about themselves and their worlds. In transformative learning, the teacher's role shifts from being a "manager" or "instructor" to a challenger, an advocate, a co-learner, an artist, a resource person, a researcher, a co-investigator, and a facilitator (Magro, 2016; Mezirow, 2000). While the teachers that I have interviewed did not necessarily use the term "transcultural" and "transformative" in expressing their approaches to literacy learning, many of their ideas and their approaches to curriculum development and assessment reflected key themes from the literature in transformative learning and transcultural literacies. (Magro, 2016; Mezirow \& Associates, 2009; Taylor, 2006).

\section{Connecting the Personal to Social Justice}

Justine, a senior high English language arts and Media Studies teacher at a large inner city adult education centre, views her role as an advocate and challenger. While the classroom can potentially be a place for students to develop self-efficacy and personal empowerment, Justine explained that students can also learn about competition, unequal self-worth, and relational aggression. Justine emphasized that news, current events, and television programs also shape her students' understanding of the world:

I draw my insights from critical pedagogy. Part of being a critical educator is seeing that there is not a single definition of hope, social justice, or equity. It is not so much about covering content as it is about the depth of understanding. Learning to me involves a process of challenging my students to look at the complexity of issues from an intersection of race identity, culture, and experience. I use international short stories to encourage cultural awareness. We do not use art and poetry enough in teaching. I challenge my students to create a visual poem and symbol book representing key themes of the stories that impacted [them the] most. I want students to leave my class having read stories set in the Middle East, Africa, and Asia. The curriculum framework has to be ever evolving; otherwise, adult will lose valuable opportunities to learn.

Justine emphasized the importance of reading and reflecting upon powerful transcultural texts to encourage critical thinking about social justice issues such as discrimination and racial prejudice:

Many of my students find Sherman Alexie's The Absolutely True Diary of a Part-Time Indianriveting. Alexie shows how trauma is part of the "normal" experience for many Indigenous people. This is a book that can help non-Indigenous students develop greater empathy for the experiences of First Nation youth living "in between worlds"-the reserve, and the larger city here they need to adapt [to] quickly in order to survive. Students who have experienced hardship and discrimination can also relate to Alexie's character Junior. He is sensitive, witty, and artistic, despite the pain of losing close family members to suicide and tragic events. He pushes on. I want my students to create a better future by learning about the inequities in our world.

Justine's emphasis on helping her students make personal connections to literature and non-fiction illustrates Mezirow's (2000) concept of "narrative reframing" or "applying a reflective insight from someone else's narrative to one's own experience" (p. 23). Interdisciplinary links between English language arts, politics, sociology, Aboriginal issues, and psychology are further explored in a context of “deeper" level learning (Magro, 2016).

Luiz has taught in Korea, Japan, and in various high schools in Winnipeg. He currently teachers courses in rhetoric, literature, and communication at an adult education centre in the city. With a background in philosophy and literature, Luiz emphasized the importance of creating a climate where a critical dialogue about world events and students' lives can occur:

The humanities can be a guide to life. I get excited by ideas and in my classes, I want to encourage a playful attitude that is 
also balanced by academic rigour. There is something spiritual and therapeutic in the study of literature that you cannot find in other disciplines. I believe that anyone can be reached through literature. A book like J.D. Salinger's Catcher in the Rye can be an exploration into identity, belonging, and the search for authenticity in a fragmented world. Charlotte Bronte's Jane Eyre is a powerful novel to open up discussions about life, death, love, friendship, the importance of having faith in yourself, and finding your way in a hostile world.

Luiz described learning as "a metaphorphosis, a disruption, and a rearranging ofoneself. It may be a violent transformation and an expedition into undiscovered regions of the self." He used words and phrases that connected learning to "journeys and expeditions into the unknown." Teachers and students are "explorers and wanderers in search of new awakenings, insights, and possibilities." Effective teaching would help adult learners understand barriers to communication, selfawareness, and empathy. Luiz explained: "we live in a time of chaos, anxiety, and disconnection. We are living in an increasingly synthetic world. It is aggressive, packaged, and formulaic. The poetry of our age is advertising! Experiences are often vicarious and there is the persistent danger of being side-tracked by artificial experiences and misunderstanding of social media."

Transcultural literacies encourage an understanding of local and global events. Naqvi (2015) writes that "identity shaping issues having to do with global events and political upheavals and our students' awareness and understanding about these events is crucial." (p. 5). Luiz emphasized that effective adult educators must be aware of the nuances in our society if meaningful conversations can occur in the classroom.

Steven, a teacher in a large adult learning centre where over 70 languages are spoken, explained the importance of encouraging students to read a range of texts that focus on a social justice theme such as exclusion, loneliness, discrimination, and ostracization. He teaches English, history, and psychology. In his classes, Steven poses questions that challenge the students to think critically about connections between local and global events. What are the similarities in patterns of colonialization, for example, that have taken place in large parts of Africa, North America, and Australia? He believes that essential questions, discussions, and research opportunities can bring to light "disruptive knowledge" so that students begin to challenge accepted beliefs and recognize alternative possibilities. The texts he chooses explore class, culture, ethnicity, religion, relationships, family, and global issues.

\section{Teaching English language arts has the potential to be transformative if teachers are knowledgeable and willing to take risks. Teaching from a social justice frame to me involves identifying the contradictions and hypocrisy in our society. Students can see these contradictions. You are helping them understand their world. There is a depth and richness in literature that is ideal for exploring social concerns such as crime, poverty, and unjust situations. Adult learners can identify with the outsider theme.}

Steven spoke of a recent book review written by a Grade 12 student who compared the experiences of racism that Ta-Nehisi Coates (2015) recounts in his memoir Between the World and Me and James Baldwin's $(1955,2012)$ modern classic Notes of a Native Son. Themes that highlight identity, belonging, and family fragmentation can become a catalyst for students to discuss and write about their own life experiences. Steven emphasized that students find it interesting to examine the way characters (some fictional, some real) cope with challenges and tragedies in life. "The challenge we have is to take steps to break down racial barriers and misconceptions." There is an emphasis on engaging students' emotions. Mezirow (2000) writes that "subjective reframing involves an intensive and difficult emotional struggle as old 
perspectives become challenged and transformed" (p. 23). Similarly, Mackeracher (1997) aptly writes that learning, particularly in adulthood" focuses primarily on "transforming or extending the meanings, values, skills, and strategies acquired in previous experiences" (p.33).

\section{Reclaiming and Rebuilding the Self in a Transforming Journey}

Transformative learning can involve significant personal change and educators often see their role as a mentor who assists learners on a journey toward building confidence and agency. Lou describes herself as an advocate, and a "challenger of misconceptions." She explains that so many of her students struggle with low selfesteem, negative body-image, and mental health challenges such as depression. "So many youth and adults at our school have been traumatized and I see myself as a challenger of their own misconceptions that they have about themselves. I want them to reverse their negative self-image and see themselves as vital and vibrant."

Lou begins her classes with reading aloud inspiring books such as The Child Called It by Dave Peltzer, Runaway by Evelyn Lau, Persepolis by Marina Satrapi, Running the Rift by Naomi Benaron and Wonder by R.J. Paladio. She integrates short films like "The River" by Ericka MacPherson and Katherena Vermette. This powerful short film presents an Indigenous perspective on the experience of searching for a loved one who has disappeared. Lou encourages her students to write about their thoughts in their individual notebooks:

Creativity to me is change and effective teaching is being open to my students' insights and observations. I see myself as a positive role model who cans the students can trust. In sharing my reading interests with my students, I am hoping that they can be inspired to read more. Rather than teach writing style from a formulaic position, I observe what the students are responding to and writing about in their notebooks. I comment, have conversations, and ask questions. I might say: 'This looks like a poem here or this could become a great tribute.'

As a facilitator and mentor, Lou helps her students "translate" their dreams into productive accomplishments. Lou also values and validates students' "vernacular" literacies by encouraging her students to link textual themes to their own personal stories and experiences. Lou's application of multimodal literacies reinforces the idea that learners can express meaning in multiple ways through music, drama, artistic creations, photography, film, poetry, and art gallery reflections. Bringing the outside community influences inside the classroom is one way to meaningfully engage adult learners in literacy development. These varied texts become catalysts that illuminate experiences; they are a catalyst that can open a dialogue where students inform and are informed by texts and other learners. Lou has opened up opportunities for her students to explore their interests and talents; literacy learning is multi-layered, and it involves personal and transformative growth. By "purposely inviting the interplay of contexts, positionality, and power, new spaces and possibilities are produced" (Honeyford \& Watt, 2017, p.6). Lou described a successful learning experience involving multi-modal texts:

Paintings tell a story and students can often connect with visual images. I asked the students to respond to Francisco Goya's 1814 painting 'The $3^{\text {rd }}$ of May' as a way of introducing themes of war and resistance when we collectively read Ishmael Beah's A Long Way Gone: Memoirs of a Boy Soldier. The students are amazed to read about Ismael's journey from despair to hope. I connect the theme of courage to their own lives. They can convey their experiences of resilience and courage through storytelling and artistic expressions.

Working toward transformative learning, in part, encourages adult learners to make significant connections between their own lives, 
diverse texts, and the larger social conditions and collective forces that impact them (King, 2005). Lou demonstrates this approach with her implementation of a transcultural curriculum that helps learners transform themselves and, ultimately, the world around them.

\section{Discussion}

Transcultural literacies and dimensions of transformative learning involve critical thinking, reflection, and openness to considering new perspectives. Rich learning experiences integrate personal and philosophical perspectives with imaginative, creative, and socio-cultural lenses. Shipp (2017) writes that "our curriculum, our rituals and routines, and intellectual connections to the texts being used in class" (p. 35). The data indicate that exploration of transcultural literacy through literary and non-fiction works can encourage transformative learning because, as Jarvis (2006) observes, "it requires students to make meaning rather than receive it" (p. 74).

The teachers in this study used texts as catalysts to encourage creative and reflective connections that link personal insights to local and global themes; learners were encouraged and allowed to make these connections because their teachers created the space for them to do so. Given today's culturally diverse classrooms, adult literacy educators can create a welcoming and safe environment that encourages varied dimensions of literacy learning. Literacy educators need to become more aware of the socio-cultural backgrounds of their students. Context, as Taylor (2009) notes, shapes adult education practices and it is through educator empathy and self-awareness that authentic relationships between teachers and learners can emerge. In the case of newcomer and refugee students, it is vital for educators to understand the complex political factors in countries worldwide that motivate individuals to seek a new life elsewhere. Adult learners are navigating unfamiliar educational, legal, political, and social terrain; in this context, it seems appropriate for the teacher to become more of a cultural guide such as those described above. Additionally, the teachers described here demonstrate that adult literacy curriculum can be dynamic, evolving, and grounded in way that value and validate learners' existing talents and experiences.

The experiences of the educators in this study also suggest that teaching in a time of change demonstrate the need for an interdisciplinary approach to curriculum planning. Literature and non-fiction can be linked to world issues, psychology, sociology, and social justice themes. From this "transformative" perspective, literacy learning is not solely a technical process but rather, it involves an opportunity to explore power structures and social conventions that are culturally situated. The teachers demonstrate that a diverse selection of texts that reflects historical, personal, and cultural themes connected to equity, oppression, the environment, mental health and overcoming obstacles could provide a foundation for critical literacy development. They also emphasized the importance of going beyond "deconstructing a text" into using a text as a vehicle to create new knowledge through poetry, artistic representations, dramatic scenarios, research, and reframing problems from multiple perspectives through letters and diary entries. Personal agency and self-expression are encouraged.

Educators like Lou also reinforce Dozier's (2017) observation that "works of art, including paintings and photography, encourage reflection, analysis, and evaluate thinking skills, that build success for students in both academic and workplace environments" (p. 27). Building on the importance of integrating philosophy, music, and visual arts 
in teaching, Kazemak and Rigg (1997) write that "the imagination is indispensable for knowing the world. It and its often-attendants of creativity, love, beauty and tradition allow us to re-vision the world, seeing it anew" (p. 136). While not stating that their approach to literacy learning was transformative or transcultural, the educators' views and practices did acknowledge that adult learning involved affective, imaginative, creative, and cognitive dimensions. Their practices highlight the way literacy learning can potentially enlighten and broaden learners' perspectives. Transformative learning, as Jarvis (2006) notes, involves thinking beyond taken for granted assumptions. Fiction, works of art, and nonfiction, in particular, can:

- offer scope for imagining alternatives-different resolutions to familiar problems, alternative lifestyles, and moral choices-And the process of trying different viewpoints is part of the formulation of a new perspective-Textual study, by its very nature, challenges certain commonly held beliefs about knowledge and the making of meaning. (Jarvis, 2006: p.77)

A goal in transcultural learning, notes Slimbach (2005), is to "open windows to reality outside ourselves" (p. 214). Along these lines, literacy can involve deeper level connections and dialogue with individuals who have different histories and experiences. An important point to note is that this study focused on the perspectives of the adult educators. Dirkx and Smith (2009) write: "ultimately whether a learning experience is transformative rests with the learner, not us as instructors or facilitators. Our work is to help learners make deep connections with the subject matter" (p. 65).

\section{Conclusion}

Transformative literacy learning embraces a diversity of approaches to textual practices that encourage a creative re-imagining of texts and discourses, identities, histories, and culture (Luke, 2004). Rich learning experiences are interpreted through personal and philosophical lenses, cultural and historical frames, and imaginative and literacy perspectives. The idea of learning as a journey and the metaphors and images associated with journeys-discovery, mapping of ideas, exploration, and navigating new cultural terrain through world literature reinforce the idea that transformative learning is multi-layered, dynamic, and improvisational. Transcultural journeys of learning involve the capacity to "put oneself in another's shoes - to apprehend their point of view and felt experiences is prerequisite to finally taking responsibility as citizens of the global community" (Slimbach, 2005, p. 218). Collectively, the adult educators' perspectives described in this study emphasize a need to move beyond a linear conceptualization of literacy into a new paradigm that crosses cultural boundaries and disciplines.

Future studies could explore specific personality attributes of adult educators who are more likely to encourage transcultural literacies and transformative types of learning. For example, a teacher's optimism, creativity, curiosity, openness to new ideas, problem solving abilities, a willingness to tolerate ambiguity, and resilience may positively impact adult learning processes. A particular text or teaching strategy could encourage a learner's motivation, problem solving ability, or creativity. Systemic barriers for adult learners continue to exist as shifting demands and pressures for accountability increase along with an erosion of resources to help adult learners with specialized needs. A committed effort on the part of researchers, practitioners, program planners, and educational policy makers is needed to address these challenges. 


\section{References}

Adichie, C.N. (2016). The danger of a single story. In L. Blass, L., M. Vargo, \& I.Wisniewska (Eds.) $21^{s t}$ century reading: Creativity and thinking and reading with TedTalks (pp. 22-25) Boston, MA: National Geographic/Cengage Learning.

Baldwin, J. (2012) Notes of a native son. Boston, MA: Beacon Press. (originally published in 1955).

Clark, M. C. (1993). Transformational learning. New Directions for Adult and Continuing Education, 57, 47-56.

Coates, T. (2015). Between the world and me. New York, NY: Spiegel and Grau.

Cranton, P. (2006). Understanding and promoting transformative learning. San Francisco, CA: Jossey-Bass.

Cuccioletta, D. (2001/2002). Multiculturalism or transculturalism?: Toward a cosmopolitan citizenship. London Journal of Canadian Studies, 17(1), 1-11.

Davis-Manigaulte, J., Yorks, L., \& Kasl, E. (2006). Expressive ways of knowing and transformative learning. New Directions for Adult and Continuing Education, 109, 27-35.

Dirkx, J., \& Smith, R.O. (2009). Facilitating transformative learning: Engaging the emotions in an online context. In J. Mezirow, E.W. Taylor, \& Associates (Eds.) Transformative learning in practice: Insights from community, workplace, and higher education (pp. 57-66). San Francisco, CA: Jossey-Bass.

Dirkx, J. (2011). The meaning and role of emotions in adult learning. In S. Merriam, \& A. Grace, (Eds.) Contemporary issues in adult education (pp. 349-362). Malabar, FL: Krieger.

Dozier, L. (2017). Art as text: Seeing beyond the obvious. English Journal,106(6), 29-34.

Freire, P. (1993). Pedagogy of the oppressed. New York: Seabury Press. (originally published in 1970).

Giroux, H. (1993). Literacy and the politics of difference. In C. Lankshear \& P. L. McLaren (Eds.), Critical literacy: politics, praxis, and the postmodern (pp. 367-378). Albany, NY: State University of New York.
Giroux, H. (2006). Cultural studies, public pedagogy, and the responsibility of intellectuals. Communication and Critical/Cultural Studies, 1(1),59-79.

Greene, M. (1995). Releasing the imagination: Essays on education, the arts, and social change. San Francisco, CA: Jossey-Bass.

Honeyford, M., \& Watt, J. (2017). Burrowing and becoming: Teaching writing in uncertain times. Pedagogies: An International Journal,1(1),1-21. doi: 10.1080/155448OX/2017.1399797.

Immigration, Refugees, and Citizenship Canada: Facts and Figures (2015). Ottawa, ON: Government of Canada. Retrieved from www.Cic.gc.ca/english/resources/ statistics/menufact.asp.

Jarvis, C. (2006). Using fiction for transformation. New Directions for Adult and Continuing Education, 109, 69-77.

Kazemak, F. E., \& Rigg, P. (1997). “...the sense of soul... goes hand in hand with an aesthetic response": Art in Adult Literacy Education. Adult Basic Education,7(3),133-144.

Kostogritz, A., \& Tsolidis, G. (2008). Transcultural literacy: Between the local and the global. Pedagogy, Culture, and Society,16 (2): 1-24.

King, K. (2005). Bringing transformative learning to life. Malabar, FL: Krieger.

King, T. (2012). The inconvenient Indian. Toronto: Doubleday Canada.

Kvale, S. (1996). Interviews: An introduction to qualitative research. Thousand Oaks, CA: Sage.

Lahiri, J. (2008). The unaccustomed earth. New York, NY: Alfred A. Knopf.

Luke, A., \& Elkins, J. (2002). Toward a critical, world literacy. Journal of Adolescent \& Adult Literacy, 45(8), 668-673.

Mackeracher, D. (1997). Making sense of adult learning. Toronto: Culture Concepts. 
Magro, K. (2016). Connections across cultures: Applications of adult learning theory to newcomer education. In G. Strohschen \& Associates (Eds.) The Metagogy Project: A theorem for a contemporary adult education praxis (pp.211-234). Atlanta, GA: American Scholars' Press.

Magro, K. \& Ghorayshi, P. (2011). Adult refugees and newcomers in the inner city of Winnipeg: Promising pathways for transformative learning. Winnipeg, MB: Canadian Centre for Policy Alternatives.

Manitoba Immigration Facts. (2016). PDF Reports. Retrieved from: www.gov.mb.ca/labour/immigration/ publication.html.

Merriam, S. \& Associates. (2007). Non-western perspectives on learning and knowing. Malabar, FL: Krieger.

Mezirow, J. (1981). A critical theory of adult learning and education. Adult Education Quarterly. 32(1),3-24.

Mezirow, J. (1991). Transformative dimensions of adult learning. San Francisco, CA: Jossey-Bass.

Mezirow, J. (2000). Learning to think like an adult: Core concepts of transformation theory. In J. Mezirow \& Associates (Eds.) Learning as transformation (pp. 3-34). San Francisco, CA: Jossey-Bass.

Mezirow, J. \& Associates (2000). Learning as transformation. San Francisco, CA: Jossey-Bass.

Mezirow, J., Taylor, E.W., \& Associates (2009). Transformative learning in practice. Insights from community, workplace, and higher education. San Francisco, CA: Jossey-Bass.

Michell, M. (2006). Teaching for critical literacy: A necessity to look deeper and beyond. English Journal, 96(2):41-46.

Miller, J.L. (2006). Curriculum studies and transnational flows and mobilities: Feminist autobiographical perspectives. Transnational Curriculum Inquiry, 3(2), 34-50.

Naqvi, R. (2015). Literacy in transcultural and cosmopolitan times. A call for change. Calgary, AL: Werklund School of Education. Retrieved from: http://www.academia.edu/169636/_Literacy_in_ Transcultural_Cosmopolitan_Times
O'Sullivan, E. (2002). The project and vision of transformative education: Integral transformative learning. In E. O’Sullivan, A. Morrel, \& M.A. O’Connor ( Eds.), Expanding the boundaries of transformative learning (pp. 1-12). London, UK: Palgrave Press.

Orellana, M., F. (2016). Immigrant children in transcultural spaces. New York, NY: Routledge.

Pennycook, A. (2007). Global Englishes and transcultural flows. New York, NY: Routledge.

Reynolds, G. (with Wanda Robson). (2016). Viola Desmond's Canada. Halifax \& Winnipeg: Fernwood Publishing.

Shipp, L. (2017). Revolutionizing the English classroom through consciousness, justice, and self-awareness. English Journal,106 (4), 35-40.

Shor, I. \& Freire, P. (1987). A pedagogy for liberation: Dialogues on transforming education with Ira Shor and Paulo Freire. New York, NY: Bergin and Garvey.

Short, K.G. (2016). A curriculum that is intercultural. In Short, K.G., Day, D., \& Schroeder, J. Teaching globally: Reading the world through literature (pp. 3-24). Portland, ME: Stenhouse Publishers.

Slimbach, R. (2005). The transcultural journey. The Interdisciplinary Journal of Study Abroad, 1(1), 205-230.

Statistics Canada (2007). Immigration in Canada: A portrait of the foreign-born population, 2006 Census. Ottawa, ON: Statistics Canada.

Street, B. (1984). Literacy in theory and practice. Cambridge, MA: Cambridge University Press.

Taylor, E. (2000). Analyzing research on transformative learning theory. In J. Mezirow \& Associates (Eds.) Learning as transformation (pp. 285-328). San Francisco, CA: Jossey-Bass.

Taylor, E. (2008). Transformative learning theory. New Directions in Adult and Continuing Education, 119, 5-16.

Taylor, E. (2009). Fostering transformative learning. In J. Mezirow, E. W. Taylor, \& Associates (Eds.) Transformative learning in practice: Insights from community, workplace, and higher education (pp. 3-14). San Francisco, CA: Jossey-Bass. 
Taylor, E.W., \& Cranton, P. (Eds.) (2012). The handbook of transformative learning. San Francisco, CA: Jossey-Bass.

UNESCO. (2010). $3^{\text {rd }}$ Global report on adult learning and education: The impact of adult learning and education on health and well-being, employment and the labour market; and social, civic, and community life. Hamburg, Germany: UNESCO Institute for Lifelong Learning.
United Nations High Commission on Refugees. (2015). Annual report on refugees. Geneva, Switzerland: United Nations.

van Manen, M. (2007). Phenomenology of practice. Phenomenology and Practice, 1(1),11-30.

Wilkerson, I. (2010). The warmth of other suns. New York, NY: Random House. 